\title{
Effect of TRX Suspension Training on Muscle Explosive Force of Police College Students
}

\author{
Fan Zhang \\ Department of Police Skills and Tactics \\ Nanjing Forest Police College \\ No. 28 Wen Lan Road, Qixia District \\ Nanjing, JIANGSU 210023 China \\ zhangfan@nfpc.edu.cn
}

\begin{abstract}
The purpose of this study was to investigate the effects of 12-week TRX suspension training and instrument resistance training on dorsal muscle strength and isometric muscle endurance of police college students. Thirty male students from Nanjing Forest Police College were randomly divided into TRX suspension training group (TRX group) and ART training group (ART group). Each group received a 90-minute training course twice a week for 12 weeks. The muscle explosive forces of all subjects were tested before and after training. After statistical analysis of $T$ test of dependent samples, it was found that TRX group has significant progress in statistical data on the muscle explosive force while the ART group has no significant progress. According to the research results of this study, it is possible to prove that TRX can be used to stabilize the core muscle group and to train the coordination of the whole body muscles in each training action. TRX suspension training is better than the resistance training because of the participation of core muscle group.
\end{abstract}

Keywords-Police college; TRX; Suspension training; Muscle explosive

\section{INTRODUCTION}

The quality of policeman's physical ability is not only the guarantee of police force, but also the cornerstone of police security enforcement. In view of the latest concept of physical training (such as TRX training and core muscle strengthening) and the actual impact of police enforcement, the development of core muscle and explosive force has gradually become the core index to measure the professional physical ability of the police. TRX has changed a lot in recent years, such as the concept of field training designed by the US Navy SEAL Team, which can be used in a convenient, effective, portable and suitable training mode for various physical abilities in a combat environment lacking resources. Using TRX as a single part of muscle training can link the core surface muscle group and core stable muscle group of human body, increase joint stability, strengthen ligaments, enhance core muscle group as well as explosive force and increase sports performance, so it can theoretically be popularized to police's professional physical training. In order to verify the difference between TRX training and traditional resistance training in muscle explosive force, this study takes TRX training (new) and traditional equipment apparatus resistance training (old) as variables to observe the influence and difference of the two training methods on the muscle explosive force of police college students, with a view to providing scientific reference for the reform of teaching content of police physical ability courses in police colleges.

\section{RESEARCH OBJECTS AND METHODS}

\section{A. Research Objects}

Thirty male college students from Nanjing Forest Police College were subjects, with an average age of $19.4 \pm 1.3$ yrs., an average height of $173.5 \pm 3.4 \mathrm{~cm}$ and an average weight of $68.7 \pm 3.9 \mathrm{~kg}$. They were randomly divided into the experimental group of 15 and the control group of 15 . The experimental group was given TRX suspension training, while the control group was given apparatus resistance training.

\section{B. Research Methods}

\section{1) Experimental Control:}

a) It is confirmed that all subjects have no cardiovascular diseases, hypertension and related visceral diseases, and can accept the maximum exercise test;

b) Subjects are not allowed to take part in any strenuous exercise or drink drinks containing caffeine, creatine, branched-chain amino acids and alcohol within 24 hours before the experiment and are required to sleep for at least 6 hours;

c) The subjects should not have any history of upper limb muscle and joint injuries in the past six months in order to avoid experimental deviation;

d) The subjects are not allowed to be engaged in strenuous exercise and produce muscle injury or soreness before the measurement on the week and day of the experiment;

e) Each measurement time is controlled in the same time period to avoid interfering variables;

f) The average height and weight of the subjects are controlled within 5 to avoid experimental errors caused by additional factors;

g) On the day of the experiment, all the subjects do not have any ongoing diseases, such as cold, fever, etc.

h) It is ensured that the subjects understand the purpose process and rights of this experiment and complete the experiment indoors. 


\section{2) Experimental Design:}

\section{a) Experimental Process}

According to the purpose of this study, all subjects were randomly divided into TRX suspension training ( TRX ) and apparatus apparatus resistance training ( ART ) for 12 weeks, twice a week for 90 minutes. The experimental process is divided into three stages: 1) Pret-test of muscle explosive force. 2) 12-week TRX suspension training and apparatus resistance training. 3) Post-test of muscle explosive force.

\section{b) Training Course}

Training course divides the 90-minute course into 3 parts:

- Warm-up exercise. It lasts 15 minutes. It takes lowintensity aerobic exercise to raise the body's working temperature, improve muscle elasticity and extensibility through dynamic stretching, increase the range of joint movement and connecting sensory and motor neurons as the main training courses and avoid sports injuries [1].

- Main courses ( TRX suspension training and equipment apparatus resistance training). It lasts 60 minutes. In this study, 10 muscle parts of the large muscle group of the body are used as the main training parts for TRX suspension training and equipment apparatus resistance training, including quadriceps femoris and biceps femoris. Table 1 shows the principles of TRX suspension training and apparatus resistance training [2].

- Relaxation exercise. It lasts 15 minutes. It takes the initiative to recover with low-intensity aerobic or stretching movements, accelerate the discharge of metabolic wastes in the body after training, relieve the tight muscle parts after training, reduce the accumulation of lactic acid and stretch the muscles of each training part, and reduce the muscle soreness and fatigue after exercise.

TABLE I. PRINCIPLES OF TRAINING

\begin{tabular}{|c|c|c|}
\hline \multirow[b]{2}{*}{ Parameter } & \multicolumn{2}{|c|}{ Training type } \\
\hline & $\begin{array}{c}\text { TRX Suspension } \\
\text { Training }\end{array}$ & Resistance Training \\
\hline Preset & \multicolumn{2}{|c|}{$\begin{array}{l}\text { Before the start of the course, the subjects are arranged to } \\
\text { experience the course description and actual operation, } \\
\text { and measure the maximum muscle strength ( } 1 \mathrm{RM}) \text { so } \\
\text { that the } 12 \text { - week training can proceed smoothly. }\end{array}$} \\
\hline $\begin{array}{l}\text { Times of } \\
\text { Repetition }\end{array}$ & \multicolumn{2}{|c|}{$\begin{array}{l}\text { According to the suggestion of ACSM ( } 2011 \text { ) of the } \\
\text { American Sports Medical Association, the recommended } \\
\text { number of repetitions for improving muscle fitness is } 8 \text { - } \\
12 \text { times. Therefore, this study adopts ACSM's } \\
\text { suggestion and sets the times of repetitions for each } \\
\text { group to } 8-12 \text { times. }\end{array}$} \\
\hline $\begin{array}{l}\text { Repeated } \\
\text { Group }\end{array}$ & \multicolumn{2}{|c|}{$\begin{array}{l}\text { In the first } 6 \text { weeks, the number of repeated groups for } \\
\text { each muscle part was } 2 \text { groups, and in the last } 6 \text { weeks, } \\
\text { the muscle fitness of TRX suspension training group and } \\
\text { equipment resistance training group was increased to } 3 \\
\text { groups. }\end{array}$} \\
\hline Load & $\begin{array}{l}\text { Adjust the load } \\
\text { intensity by angle, } \\
\text { based on the number of } \\
\text { repetitions of } 8 \sim 12 .\end{array}$ & $\begin{array}{l}\text { Based on the maximum } \\
\text { muscle strength ( } 1 \mathrm{RM}) \text { of } \\
70 \% \sim 80 \% \text {, the number of } \\
\text { repetitions should be } 8 \sim 12 .\end{array}$ \\
\hline
\end{tabular}

\section{3) Training Method:}

\section{a) Quadriceps femoris Training}

TRX group: The subjects adjust the load with $8 \sim 12 \mathrm{RM}$ repetitions, with the body facing the anchor point ( TRX binding position ), with hip and knee flexion and quadriceps contraction as the main movements, using body weight and arm strength as the load. The lighter the load is assisted by the force of the arm with both feet on the ground, the heavier the load is assisted by the light grip of the arm with one foot off the ground.

ART group: With hip and knee joint stretching and quadriceps contraction as the main movements, the number of bars is adjusted by $8 \sim 12 \mathrm{RM}$ to determine the weight load, as shown in Table 2.

TABLE II. QUADRICEPS FEMORIS TRAINING

\begin{tabular}{|c|c|c|}
\hline \multirow{2}{*}{ Type } & \multicolumn{2}{|c|}{ Weight } \\
\hline & Low & High \\
\hline TRX & & \\
\hline ART & & \\
\hline
\end{tabular}

b) Biceps femoris Training

TRX group: The subjects adjust the load with $8 \sim 12 \mathrm{RM}$ repetitions, lie on your back and hang your feet under the anchor point ( TRX binding position ), with knee flexion and contraction of biceps femoris as the main actions, using your body as a load, hip flexion will gently hook your feet inward, and hip stabilization will also hook your feet inward .

ART group: The knee flexion and contraction of biceps femoris are the main actions, and the number of bars is adjusted by $8 \sim 12 \mathrm{RM}$ to determine the weight load, as shown in Table 3 .

TABLE III. BICEPS FEMORIS TRAINING

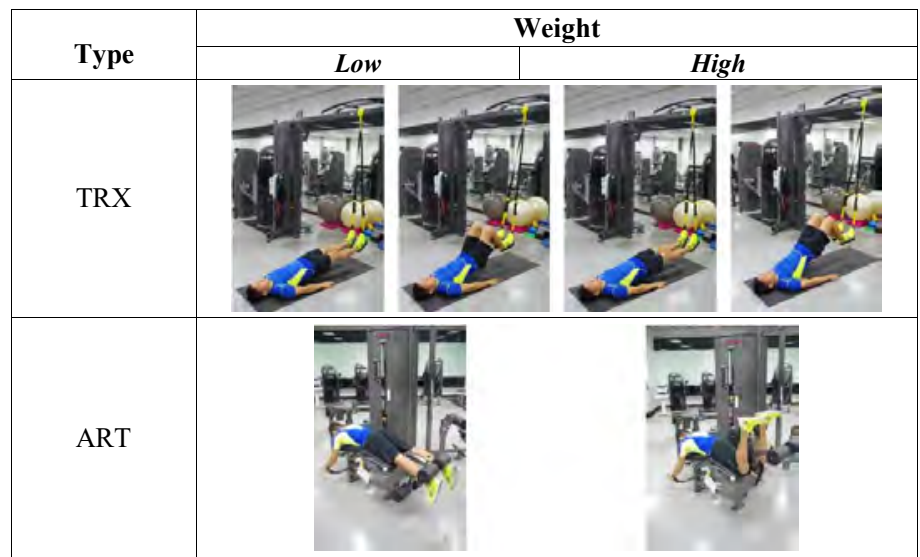


4) Experimental Indicators(Muscle Explosive Force Test): Equipment: electronic vertical jump tester.

Steps:

- The subject stands the subject directly under the tester and straightens both hands on the board marked on the upper layer in an upright position.

- The subject straightens his hands with his feet and toes against the wall, pushes the board on the marking layer to the highest position with his middle fingers, and measures the starting point for the vertical jump.

- The subject slaps the measuring board to obtain data when the feet jump up to the highest point after crouching on the knees during the test.

- The subject takes the best score record twice for each subject, as shown in fig. 1 .

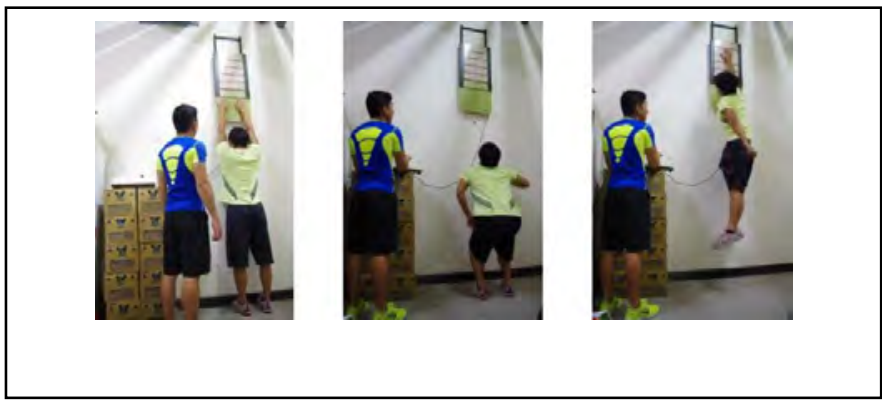

Fig. 1. Vertical jump test.

\section{5) Statistical processing and analysis.}

SPSS 19.0 was used for statistical processing, and the results were expressed by means standard deviation $(\bar{X} \pm \mathrm{SD})$. The basic data of TRX suspension training group and instrument apparatus resistance training group were analyzed by independent sample $T$ test. The influence of TRX suspension training group and instrument apparatus resistance training group on core muscle group and explosive force was compared by paired sample $\mathrm{T}$ test. Statistically the significant level was $P<0.05$ and the extremely significant level was for $P<0.01$.

\section{RESULTS AND ANALYSIS}

For TRX suspension training group, the average of vertical jump before the exercise intervention was 40.57 \pm 7.04 . After the exercise intervention. The result was $43.86 \pm 6.09$. For the apparatus resistance training group, the average of explosive force before the exercise intervention was $41.43 \pm 5.06$. After exercise intervention, the result was $44.14 \pm 7.27$. The results showed that the TRX suspension training group and the apparatus resistance training group were different before and after the training of the muscle explosive force after the exercise intervention, and the result showed that there was a significant improvement in the explosive force after the exercise intervention $(\mathrm{P}<0.05)$. The apparatus resistance training group had no significant progress in the explosive force after the Movement Intervention $(P>0.05)$. Table 4 shows the difference of the effect between TRX Suspension
Training and apparatus resistance training on muscle explosive force.

TABLE IV. COMPARISON OF VERTICAL JUMP

\begin{tabular}{|c|c|c|c|c|}
\hline \multirow{2}{*}{ Test } & group & Pre-test & Post-test & P \\
\hline \multirow{2}{*}{$\begin{array}{c}\text { vertical } \\
\text { jump }\end{array}$} & TRX & $40.57 \pm 7.04$ & $43.86 \pm 6.09$ & $0.021^{*}$ \\
\cline { 2 - 5 } & ART & $41.43 \pm 5.06$ & $44.14 \pm 7.27$ & 0.122 \\
\hline
\end{tabular}

The results of this study found that TRX suspension training group and the apparatus resistance training group after 12 weeks of training sessions. TRX suspension training group in statistical data on the explosive force has significant progress $(\mathrm{P}<0.05)$, the apparatus resistance training group in the statistical data on the explosive force is no significant progress $(\mathrm{P}>0.05)$, on the statistical data only TRX suspension training group has significant progress, which conforms to the effects. such as 16 high school swimmers involved in 8 weeks of core training, the results show that the core training group in the explosive power project and the control group have significant differences [3]; The effect of the training of nuclear myocardium and the enhancement training on rugby players' special athletic performance found that core muscle group training can improve speed, explosive force, coordination and stability [4]. The effect of the 8-week core training on the students' vertical jumping and stability limit, the results show that the core training can improve the students' jumping performance [5].The effect of 8-week core training on the students' agility and jumping ability, the results show that the eight-week core training can improve the students' agility and jumping ability [6]. According to the above literatures and the research results of this study, it is possible to prove that TRX suspension training can be used to stabilize the core muscle group and to train the coordination of the whole body muscles in each training action. TRX suspension training is better than the apparatus resistance training of the device because of the participation of core muscle group.

\section{CONCLUSION}

The results showed that the training effect of TRX suspension training on the muscle explosive force of police college students has been significantly improved, and the training effect of apparatus resistance training on the muscle explosive force of police college students has not been significantly improved. The introduction of TRX training mode into the basic physical education curriculum in police college can effectively train the core muscle group and explosive force (the foundation of effective execution of police technical and tactical ability), which is a useful attempt and an effective supplement to the traditional physical training mode. Compared with resistance training, it is found that TRX suspension training and can significantly enhance the muscle explosive force. This result can provide scientific reference and practice for the teaching content reform of the basic physical education in our school. 


\section{ACKNOWLEDGMENT}

This work was supported in part by the 13th Five-Year plan project of Jiangsu Education Science under Grant Cc/2018/01/11, in part by Jiangsu University Philosophy and Social Sciences Research Fund Project under Grant 2017SJB0590, in part by Nanjing Forest police College Teaching Reform Project under Grant ZD18104, in part by Jiangsu Qing Lan Project under Grant 2017, and in part by Preresearch project of Nanjing Forest police College under Grant LGY201603.

\section{REFERENCES}

[1] Byrne, J. M., et al., "Effect of using a suspension training system on muscle activation during the performance of a front plank exercise," Journal of Strength \& Conditioning Research, vol. 28, pp. 3049-3050, November 2014.

[2] Angus. G, Tobias. M, "TRX Suspension Training: A New Functional Training Approach for Older Adults - Development, Training Control and Feasibility," International Journal of Exercise Science, vol. 8, pp. 224-233, March 2015.

[3] Atkins. S. J, Bentley. I, Brooks. D, et al., "Electromyographic response of global abdominal stabilizers in response to stable- and unstable-base isometric exercise," Journal of Strength \& Conditioning Research, vol. 29, pp. 1609-1613, June 2015.

[4] Cugliari. G, Boccia. G, "Core Muscle Activation in Suspension Training Exercises,” Journal of Human Kinetics, vol. 56, pp. 61-71, March 2017.

[5] Borreani. S, Calatayud. J, Colado. J. C, et al., "Muscle activation during push-ups performed under stable and unstable conditions," Journal of Exercise Science \& Fitness, vol. 13, pp.94-98, February 2015.

[6] Mok. N. W, Yeung. E. W, Cho. J. C, et al., "Core muscle activity during suspension exercises," Journal of Science \& Medicine in Sport, vol. 18, pp. 189-194, March 2015. 